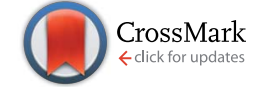

Cite this: RSC Adv., 2017, 7, 764

Received 22nd October 2016 Accepted 18th November 2016

DOI: 10.1039/c6ra25666j

www.rsc.org/advances

\section{A highly efficient heterogeneous copper-catalyzed chlorodeboronation of arylboronic acids leading to chlorinated arenes}

\begin{abstract}
Wen He, ${ }^{\text {ab }}$ Rongli Zhang ${ }^{a}$ and Mingzhong Cai ${ }^{\star a}$
A highly efficient heterogeneous copper-catalyzed chlorodeboronation of arylboronic acids with inexpensive $\mathrm{N}$-chlorosuccinimide (NCS) was achieved in MeCN in the presence of $10 \mathrm{~mol} \%$ of L-prolinefunctionalized MCM-41-immobilized copper(I) complex [MCM-41-L-proline-CuCl] under mild conditions, yielding a variety of aryl chlorides in excellent yields. This method proved to be tolerant of a broad range of functional groups and particularly useful for the conversion of electron-deficient arylboronic acids to aryl chlorides, a transformation that is inefficient without copper catalysis. This heterogeneous copper catalyst can be recovered by a simple filtration of the reaction solution and recycled for at least 10 times without any decreases in activity.
\end{abstract}

\section{Introduction}

Aryl chlorides are frequently found as a structural motif in a wide variety of natural products, pharmaceuticals, and agrochemicals $^{1}$ and they are also ubiquitous synthetic intermediates in organic chemistry that are used for numerous transformations. ${ }^{2}$ Therefore, the development of general, regioselective and practical methods for the synthesis of functionalized aryl chlorides is of great importance. Traditional methods for the preparation of chlorinated arenes such as the Sandmeyer reaction ${ }^{3}$ and direct electrophilic aromatic substitution ${ }^{4}$ usually suffer from one or more limitations including poor regioselectivity and chemoselectivity, low yield, harsh reaction conditions, long reaction times, and tedious reaction procedures. The palladium-catalyzed regio- and chemoselective $\mathrm{C}-\mathrm{H}$ chlorination of electron-deficient arenes with NCS and the conversion of aryl triflates to aryl chlorides were reported, ${ }^{5}$ however, the use of a toxic and expensive palladium and a phosphine ligand limited their application. Very recently, electrophilic chlorination of arenes and heterocycles by using 1-chloro-1,2-benziodoxol-3one as a new chlorinating reagent ${ }^{6}$ or triphenylphosphine sulfide as Lewis base catalyst with $\mathrm{NCS}^{7}$ due to the lower inherent reactivity of NCS has proven to be efficient routes to aromatic chlorides. The boron-halogen exchange reaction has emerged as a means by which halogenated arenes can be produced due to the wide variety of commercially available boronic acids and derivatives in recent years, ${ }^{8}$ however, the majority of these transformations have been directed at the

${ }^{a}$ Key Laboratory of Functional Small Organic Molecule, Ministry of Education, College of Chemistry \& Chemical Engineering, Jiangxi Normal University, Nanchang 330022, P. R. China

bJiangxi Cancer Hospital, Nanchang 330029, P. R. China. E-mail: mzcai@jxnu.edu.cn preparation of aryl iodides, bromides, ${ }^{9}$ and fluorides, ${ }^{10}$ the analogous boron-chloride exchange reaction with NCS fails or has limited scope, presumably due to the lower reactivity of NCS. ${ }^{9 c_{f} f}$ Hartwig et al. showed that $\mathrm{CuCl}_{2}$ can effectively mediate the chlorination of arylboronates with NCS, but the use of excess of $\mathrm{CuCl}_{2}$ (3.5 equiv.) was needed to obtain high yields. ${ }^{11}$ Recently, Wu and Hynes reported a copper-catalyzed chlorination of functionalized arylboronic acids with NCS. ${ }^{12}$ Molander et al. described a metal-free chlorodeboronation of organotrifluoroborates with trichloroisocyanuric acid (TCICA) as chlorinating agent to prepare aryl chlorides. ${ }^{13}$

Although the copper-catalyzed or mediated chlorodeboronation of arylboronic acids or arylboronates with inexpensive NCS was highly efficient methods for the construction of aryl chlorides, the use of 1.0 or 3.5 equiv. of copper salts was required to obtain high yields. Moreover, homogeneous copper salt is difficult to be separated from the reaction mixture and can not be reused in consecutive reactions. It is well known that homogeneous catalysis might result in heavy metal contamination of the desired isolated product, which restricts the application of such systems in electronics and biomedicine. These problems are of particular environmental and economic concerns in large-scale syntheses and industry. To overcome these problems, the development of highly efficient and recyclable heterogeneous catalysts, for example by immobilization of catalytically active species onto an ideal solid support to produce a molecular heterogeneous catalyst is essential. ${ }^{14}$ The use of supported catalysts could result in easy recovery and recyclability of the copper catalyst, thereby, minimizing copper contamination of the desired isolated products and wastes derived from reaction workup.

The discovery of mesoporous MCM-41 materials has provided a new possible candidate for an ideal heterogeneous 


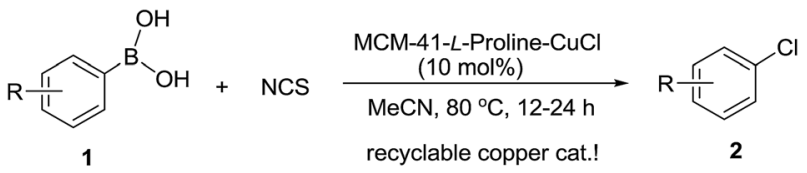

$\mathrm{R}=$ alkyl, aryl, $\mathrm{CF}_{3}, \mathrm{NO}_{2}, \mathrm{CN}, \mathrm{OH}$, amino, ether, ester, aldehyde, ketone, amide

Scheme 1 Heterogeneous Cu-catalyzed chlorination of arylboronic acids with NCS.

support for the immobilization of homogeneous catalysts and given an enormous stimulus to research in heterogeneous catalysis. ${ }^{15}$ The MCM-41 has high surface area, large and defined pore size, big pore volume and rich silanol groups in the inner channel walls. ${ }^{16}$ To date, MCM-41-immobilized palladium, ${ }^{17}$ rhodium, ${ }^{18}$ molybdenum, ${ }^{19}$ gold, ${ }^{20}$ and copper $^{21}$ complexes have been successfully utilized as potentially green and sustainable catalysts in organic synthesis. Recently, we reported the first synthesis of L-proline-functionalized MCM-41immobilized copper(I) complex [MCM-41-L-proline-CuCl] and its successful application to Chan-Lam coupling reaction between sulfonyl azides and arylboronic acids. ${ }^{22}$ In continuing our efforts to develop greener synthetic pathways for organic transformations, ${ }^{17 \boldsymbol{d}-\mathbf{f , 2 1 , 2 2}}$ herein we wish to report a highly efficient heterogeneous copper-catalyzed chlorodeboronation of functionalized arylboronic acids with NCS by using $10 \mathrm{~mol} \%$ of MCM-41-L-proline-CuCl complex as catalyst, yielding a variety of functionalized aryl chlorides in excellent isolated yields (9098\%) (Scheme 1). This heterogeneous copper catalyst can easily be recovered by a simple filtration of the reaction solution, and its catalytic efficiency remains unaltered even after recycling ten times.

\section{Results and discussion}

A series of L-proline-functionalized MCM-41-immobilized copper(I) or copper(II) complexes [MCM-41-L-proline-CuX ${ }_{n}$ ] were prepared from commercially available and inexpensive reagents and simple copper salts such as $\mathrm{CuX}$ or $\mathrm{CuX}_{2}(\mathrm{X}=\mathrm{Cl}, \mathrm{Br}, \mathrm{I})$ according to our previous procedure (Scheme 2). ${ }^{22}$ Firstly, the mesoporous material MCM-41 was reacted with 4-(chloromethyl)phenyltrichlorosilane in toluene at $100{ }^{\circ} \mathrm{C}$ for $24 \mathrm{~h}$, followed by the treatment with anhydrous ethanol at $80{ }^{\circ} \mathrm{C}$ for $24 \mathrm{~h}$ and then the silylation with $\mathrm{Me}_{3} \mathrm{SiCl}$ in toluene at room temperature for $24 \mathrm{~h}$ to generate the chloromethylfunctionalized MCM-41 (MCM-41- $\left.\mathrm{CH}_{2} \mathrm{Cl}\right)$. The latter was then reacted with $\mathrm{N}$-Boc-trans-4-hydroxy-L-proline in the presence of $\mathrm{NaH}$ in THF, followed by deprotection with TFA in $\mathrm{CH}_{2} \mathrm{Cl}_{2}$ to afford the L-proline-functionalized MCM-41 (MCM-41-Lproline). Finally, the coordination reaction of MCM-41-L-proline with various copper salts in acetone at room temperature for $12 \mathrm{~h}$ afforded a series of L-proline-functionalized MCM-41immobilized copper(I) or copper(II) complexes [MCM-41-Lproline- $\mathrm{CuX}_{n}$ ] as pale blue powders.

In our initial screening experiments, the halogenation reaction of 3-nitrobenzene boronic acid 1a was investigated to optimize the reaction conditions, and the results are summarized in Table 1. At first, the temperature effect was examined by using MCM-41-L-proline-CuCl (A) (10 mol\%) as catalyst and NCS as chlorinating agent in MeCN (Table 1, entries 1-4). It is evident that the reaction proceeded very slowly at room temperature and only a trace of desired product $2 \mathbf{a}$ was detected after $48 \mathrm{~h}$. Both the reaction rate and yield increased obviously with the increase in temperature. When the reaction was carried out at $80{ }^{\circ} \mathrm{C}$, 3-nitrochlorobenzene 2 a was isolated in $97 \%$ yield within 12 h. When 1,3-dichloro-5,5-dimethylhydantoin (DCDMH) was used as chlorinating agent, the Cu-catalyzed chlorination reaction also proceeded smoothly at $80{ }^{\circ} \mathrm{C}$ to give 2a in excellent yield (entry 5). The MCM-41-L-proline- $\mathrm{CuCl}_{2}$ (D) was an alternative copper catalyst for the chlorination reaction and afforded a 95\% yield of 2a under the same conditions (entry 6). In addition, MCM-41-L-proline-CuBr (B)/NBS and MCM-41-Lproline-CuI (C)/NIS combinations were also found to give the corresponding bromo (3a) and iodo (4a) analogues in 98 and $90 \%$ yield, respectively (entries 7 and 8). We next examined the effect of the amount of the copper catalyst on the reaction.
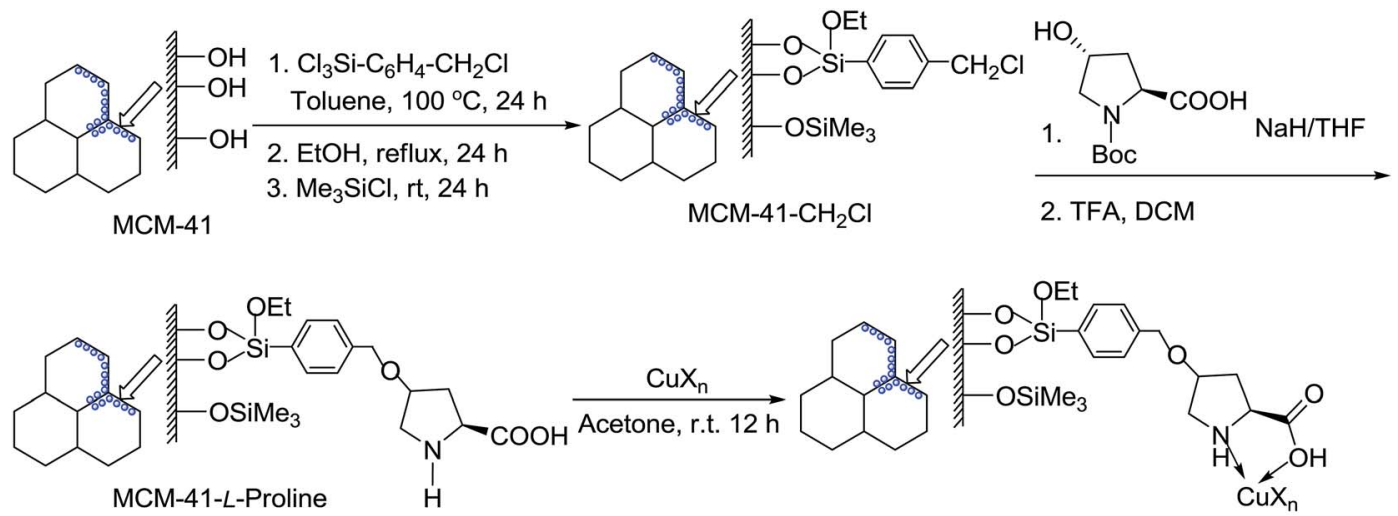

\footnotetext{
MCM-41-L-Proline-CuCl [A], CuX $\mathrm{n}_{\mathrm{n}}=\mathrm{CuCl}$ MCM-41-L-Proline-CuBr [B], CuX $=\mathrm{CuBr}$ MCM-41-L-Proline-Cul [C], CuX $=$ Cul MCM-41-L-Proline-CuCl ${ }_{2}$ [D], CuX ${ }_{n}=\mathrm{CuCl}_{2}$
}

Scheme 2 Preparation of MCM-41-L-proline-CuX $\mathrm{X}_{n}$ complexes. 
Table 1 Optimization of reaction conditions for the halogenation of 3-nitrophenylboronic acid ${ }^{a}$

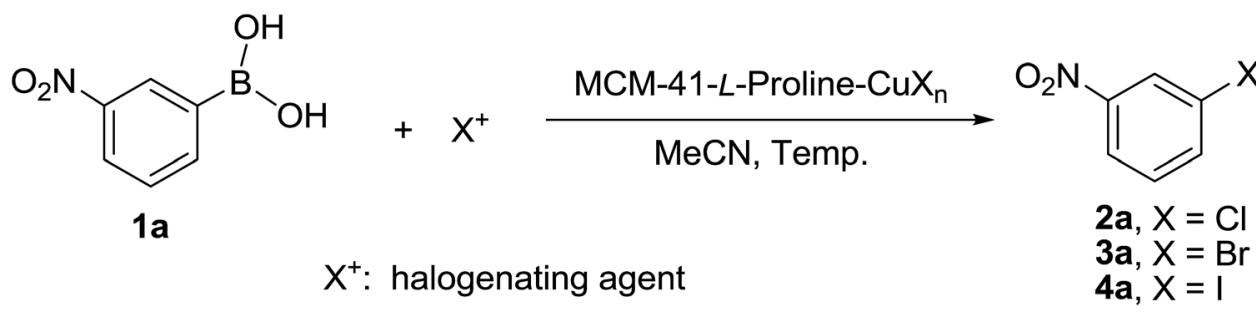

\begin{tabular}{|c|c|c|c|c|c|}
\hline Entry & Cu catalyst (mol\%) & $\mathrm{X}^{+}$(1 equiv.) & Temperature $\left({ }^{\circ} \mathrm{C}\right)$ & Time (h) & Yield $^{b}(\%)$ \\
\hline 1 & $\mathbf{A}(10)$ & NCS & 25 & 48 & Trace \\
\hline 2 & $\mathbf{A}(10)$ & NCS & 40 & 36 & 56 \\
\hline 4 & $\mathbf{A}(10)$ & NCS & 80 & 12 & 97 \\
\hline 5 & $\mathbf{A}(10)$ & $\mathrm{DCDMH}^{c}$ & 80 & 12 & 98 \\
\hline 6 & $\mathbf{D}(10)$ & NCS & 80 & 12 & 95 \\
\hline 9 & $\mathbf{A}(5)$ & NCS & 80 & 24 & 85 \\
\hline 10 & $\mathbf{A}(20)$ & NCS & 80 & 8 & 97 \\
\hline 11 & & NCS & 80 & 24 & Trace \\
\hline 12 & & NBS & 80 & 24 & 20 \\
\hline 13 & & NIS & 80 & 24 & 43 \\
\hline
\end{tabular}

${ }^{a}$ Reaction conditions: 3-nitrobenzene boronic acid 1a $(0.5 \mathrm{mmol}), \mathrm{X}^{+}(0.5 \mathrm{mmol})$ in MeCN $(2 \mathrm{~mL}) .{ }^{b}$ Isolated yield. ${ }^{c}$ DCDMH $=1,3-\mathrm{dichloro}-5,5-$ dimethylhydantoin.

Reducing the amount of the catalyst to $5 \mathrm{~mol} \%$ resulted in a lower yield and a long reaction time was required (entry 9). Increasing the amount of the catalyst could shorten the reaction time, but did not improve the yield (entry 10). Control experiments showed that only a trace of desired product 2a was observed in the absence of copper catalyst, while the bromination or iodination of $\mathbf{1 a}$ also gave the corresponding $\mathbf{3 a}$ and $\mathbf{4 a}$ in only low yields, which confirming the catalyst role of the MCM41-L-proline-CuX complexes (entries 11-13). Thus, the optimized reaction conditions for the chlorodeboronation of $\mathbf{1 a}$ are the MCM-41-L-proline-CuCl (10 mol\%), NCS ( 1 equiv.) in MeCN at $80{ }^{\circ} \mathrm{C}$ for $12 \mathrm{~h}$ (entry 4 ).

With the optimized conditions in hand, we then investigated the scope of this heterogeneous copper-catalyzed chlorodeboronation reaction using a wide range of functionalized boronic acids as the substrates and the results are listed in Table 2. In all cases, the copper-catalyzed chlorodeboronation proved highly efficient (90-98\% isolated yield). Arylboronic acids with electron-donating groups $\mathbf{1 b - 1 g}$ underwent the chlorination reaction with NCS smoothly to give the corresponding electron-rich aryl chlorides $\mathbf{2 b - 2} \mathbf{g}$ in $\mathbf{9 2 - 9 8 \%}$ yields. However, arylboronic acids having strong electron-donating groups $\mathbf{1 h}-\mathbf{1 k}$ showed relatively lower reactivity under the optimized reaction conditions, $20 \mathrm{~mol} \%$ of copper catalyst was used and a longer time ( $24 \mathrm{~h}$ ) was required to obtain high yields. For electron-deficient arylboronic acids 11-1r, they exhibited as high reactivity as $\mathbf{1 a}$ and the chlorodeboronation reactions proceeded very smoothly to furnish the corresponding electrondeficient aryl chlorides 21-2r in excellent yields (95-98\%) within
$12 \mathrm{~h}$. 4-Hydroxymethylbenzene boronic acid $1 \mathrm{~s}$ and a heteroaryl boronic acid 1t could also undergo effectively the chlorination reaction with NCS under the optimized reaction conditions to give the desired products $2 \mathrm{~s}$ and $2 \mathrm{t}$ in excellent yields. A wide range of functional groups such as nitro, trifluoromethyl, hydroxy, amino, ether, nitrile, ketone, aldehyde, ester, and amide were well tolerated. Interestingly, bulky 1-naphthylboronic acid $1 \mathbf{u}$ also gave a $95 \%$ yield of 1 -chloronaphthalene $2 \mathbf{u}$. It is noteworthy that, although the sterically hindered arylboronic acids such as 2-methylphenylboronic acid 1v, 2-biphenylboronic acid 1w, and 2,6-dimethylphenylboronic acid $\mathbf{1 x}$ also exhibited lower reactivity under the optimized conditions, the corresponding chlorinated arenes $2 \mathbf{v}-2 \mathbf{x}$ could be isolated in $90-$ $94 \%$ yields in the presence of $20 \mathrm{~mol} \%$ of MCM-41-L-proline$\mathrm{CuCl}$ complex on longer reaction times. The present protocol provides a mild, general, highly efficient and practical route to a wide variety of functionalized aryl chlorides.

Encouraged by the above results, the bromination of arylboronic acids with NBS was then examined to further expand application of this heterogeneous copper-catalyzed halodeboronation reaction, and the results are listed in Table 3. Generally, all the bromodeboronation reactions with NBS proceeded in almost quantitative yields in the presence of $10 \mathrm{~mol} \%$ of MCM-41-L-proline- $\mathrm{CuBr}[\mathrm{B}]$ in $\mathrm{MeCN}$ at $80^{\circ} \mathrm{C}$. Both electrondeficient and electron-rich aryl bromides $\mathbf{3 a}-\mathbf{3} \mathbf{i}$ were obtained in 96-98\% isolated yields by this method from the corresponding arylboronic acids. Even for arylboronic acids bearing a strong electron-donating group, the bromination reaction also proceeded effectively to afford the desired aryl bromides $\mathbf{3 g}$ and $\mathbf{3 h}$ 
Table 2 Substrate scope for heterogeneous copper(I)-catalyzed conversion of arylboronic acids to aryl chlorides ${ }^{a, b}$

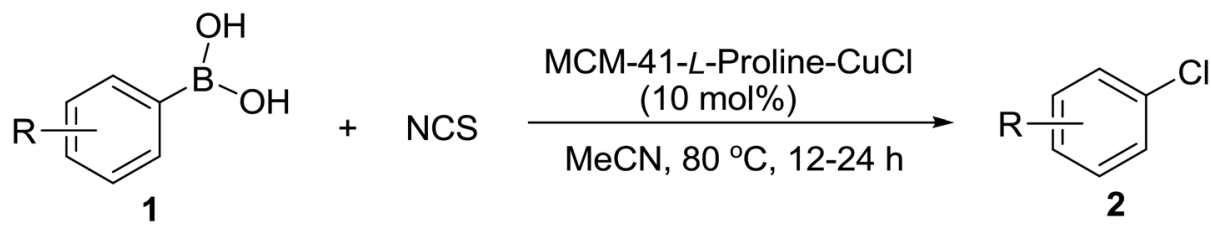<smiles>O=[N+]([O-])c1cccc(Cl)c1</smiles>

2a, $97 \%, 12 \mathrm{~h}$<smiles>Cc1ccc(-c2ccccc2)cc1</smiles>

2b, $98 \%, 12$ h<smiles>CC(=O)Nc1cccc(Cl)c1</smiles>

2c, $95 \%, 12 \mathrm{~h}$<smiles>CC(C)(C)OC(=O)Nc1ccc(Cl)cc1</smiles>

2d, $94 \%, 12 \mathrm{~h}$<smiles>O=C(Nc1ccc(Cl)cc1)OCc1ccccc1</smiles><smiles>CS(=O)(=O)Nc1ccc(Cl)cc1</smiles>
2f, $94 \%, 12 \mathrm{~h}$<smiles>CC(=O)Oc1ccc(Cl)cc1</smiles>

2g, $93 \%, 12 \mathrm{~h}$<smiles>COc1ccccc1Cl</smiles>
2h, 90\%[c], 24 h<smiles>COc1cccc(Cl)c1</smiles>

2i, $93 \%{ }^{[c]}, 24 \mathrm{~h}$
$2 e, 92 \%, 12 \mathrm{~h}$<smiles>Clc1ccc2c(c1)OCO2</smiles>

$2 \mathbf{k}, 90 \%{ }^{[\mathrm{c}]}, 24 \mathrm{~h}$<smiles>N#Cc1ccc(Cl)cc1</smiles><smiles>N#Cc1cccc(Cl)c1</smiles>

$2 \mathrm{~m}, 97 \%, 12 \mathrm{~h}$

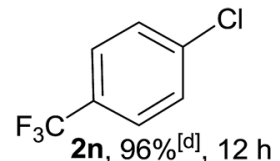<smiles>N#COc1cc(Cl)ccc1C=O</smiles><smiles>CC(=O)c1ccc(Cl)cc1</smiles><smiles>CC(=O)c1ccc(Cl)cc1</smiles><smiles>CCOC(=O)c1ccc(Cl)cc1</smiles>

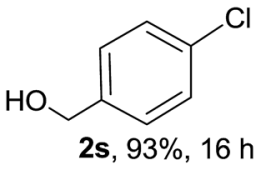<smiles></smiles><smiles>Clc1cccc2ccccc12</smiles>

$2 u, 95 \%, 12 \mathrm{~h}$<smiles>O=[N+]([O-])c1ccccc1Cl</smiles>

2v, $94 \%[\mathrm{c}, \mathrm{d]}, 20 \mathrm{~h}$<smiles>Clc1ccccc1-c1ccccc1</smiles>

$2 w, 92 \%{ }^{[c]}, 24 \mathrm{~h}$<smiles>Cc1cccc(C)c1Cl</smiles>

$2 x, 90 \%{ }^{[c]}, 24 \mathrm{~h}$

${ }^{a}$ Reaction conditions: arylboronic acid $1(0.5 \mathrm{mmol})$, NCS $(0.5 \mathrm{mmol}), \mathrm{MCM}-41$ - - - proline-CuCl $(0.05 \mathrm{mmol})$ in MeCN $(2 \mathrm{~mL})$ at $80{ }^{\circ} \mathrm{C} .{ }^{b}$ Isolated yield. ${ }^{c}$ The copper catalyst $(0.1 \mathrm{mmol})$ was used. ${ }^{d}$ Yield was determined by analytical HPLC due to product volatility.

in excellent yields within $12 \mathrm{~h}$, which indicating that NBS has higher reactivity than NCS in the halodeboronation reaction.

To verify whether the observed catalysis was due to the heterogeneous catalyst MCM-41-L-proline-CuCl or to a leached copper species in solution, we performed the hot filtration test. $^{23}$ The chlorination of 3-nitrobenzene boronic acid (1a) with NCS was carried out until an approximately $50 \%$ conversion of 1a was reached. Then the MCM-41-L-proline-CuCl was removed from the reaction mixture by filtration and the filtrate was allowed to react further at $80{ }^{\circ} \mathrm{C}$ for $8 \mathrm{~h}$. The catalyst filtration was performed at the reaction temperature $\left(80^{\circ} \mathrm{C}\right)$ to avoid possible recoordination or precipitation of soluble copper upon cooling. In this case, no significant increase in conversion of 1a was observed, demonstrating that leached copper species from the heterogeneous catalyst (if any) are not responsible for the observed activity. It was confirmed by ICP-AES analysis that no copper species could be detected in the solution (below the detection limit). These results rule out any contribution to the observed catalysis from a homogeneous copper species, indicating that the observed catalysis was intrinsically heterogeneous.

This heterogeneous copper(I)-catalyzed halodeboronation reaction of arylboronic acids with NXS may proceed through a mechanism analogous to that proposed for $\mathrm{CuX}$ (Scheme 3). ${ }^{12}$ Oxidative addition of the corresponding $N$-halosuccinimide to the MCM-41-L-proline- $\mathrm{Cu}(\mathrm{I}) \mathrm{X}$ would generate an MCM-41immobilized L-proline (2,5-dioxopyrrolidin-1-yl)Cu(III) $\mathrm{X}_{2}$ complex intermediate (A). Subsequent transmetalation with an arylboronic acid 1 would produce an MCM-41-immobilized Lproline $\mathrm{Ar}-\mathrm{Cu}(\mathrm{III}) \mathrm{X}_{2}$ complex intermediate (B). The latter can undergo reductive elimination to provide the desired aryl halide 2 and regenerate the MCM-41-L-proline-Cu(I)X complex.

For the practical application of a heterogeneous transitionmetal catalyst system, its stability and reusability are 
Table 3 Bromide formation with catalytic MCM-41-L-proline-CuBr and NBS ${ }^{a, b}$

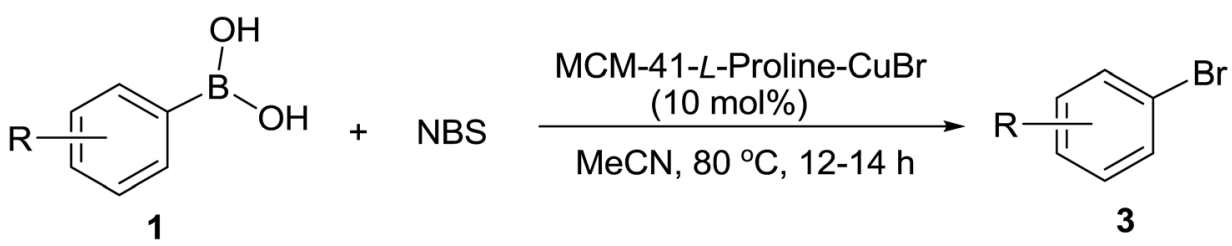<smiles>O=[N+]([O-])c1cccc(Br)c1</smiles>

3a, $98 \%, 12 \mathrm{~h}$<smiles>Brc1ccc(-c2ccccc2)cc1</smiles>

3f, $98 \%, 12 \mathrm{~h}$<smiles>N#Cc1ccc(Br)cc1</smiles>

3b, $97 \%, 12$ h<smiles>COc1ccccc1Br</smiles>

3g, $97 \%, 12 \mathrm{~h}$<smiles>O=Cc1ccc(Br)cc1</smiles>

3c, $98 \%, 12 \mathrm{~h}$<smiles>CC(=O)c1ccc(Br)cc1</smiles><smiles>CC(=O)c1ccc(Br)cc1</smiles>

3e, $98 \%, 12 \mathrm{~h}$<smiles>COc1ccc(Br)cc1</smiles>

3h, $96 \%, 12$ h<smiles>Brc1cccc2ccccc12</smiles>

3i, $98 \%, 14 \mathrm{~h}$

${ }^{a}$ Reaction conditions: arylboronic acid 1 (0.5 mmol), NBS $(0.5 \mathrm{mmol}), \mathrm{MCM}-41$-L-proline-CuBr $(0.05 \mathrm{mmol})$ in $\mathrm{MeCN}(2 \mathrm{~mL})$ at $80{ }^{\circ} \mathrm{C} .{ }^{b}$ Isolated yield.

important factors. We next examined the recyclability of the MCM-41-L-proline-CuCl complex by using the chlorination of 4biphenylboronic acid $\mathbf{1 b}(0.5 \mathrm{mmol})$ with NCS $(0.5 \mathrm{mmol})$ in MeCN $(2 \mathrm{~mL})$ at $80{ }^{\circ} \mathrm{C}$ for $12 \mathrm{~h}$. After carrying out the reaction, the catalyst was separated by a simple filtration and washed with acetone and $\mathrm{MeOH}$. After being air-dried, it can be reused directly without further purification. The recovered copper catalyst was used in the next run, and almost consistent activity was observed for ten consecutive cycles (Fig. 1). In addition, copper leaching in the supported catalyst was also determined. The copper content of the catalyst was found by ICP analysis to

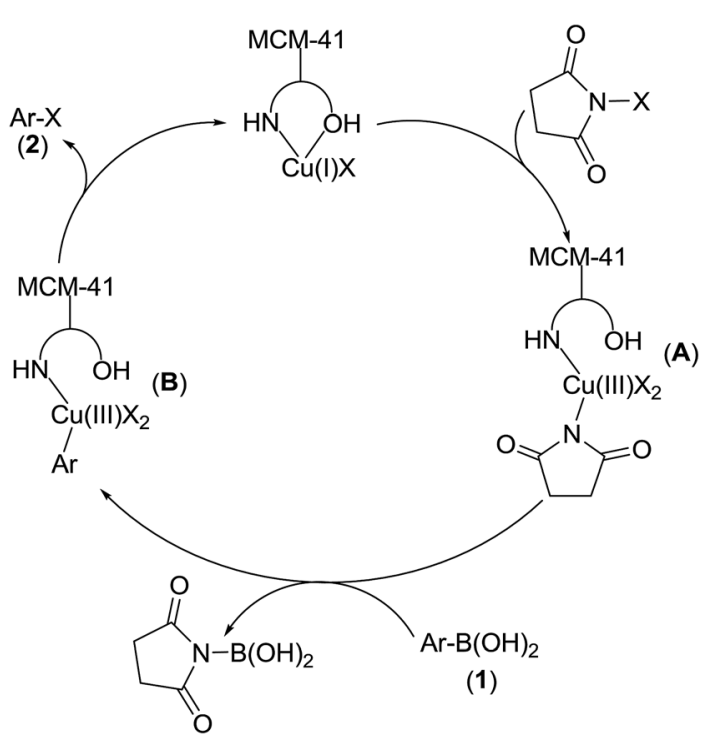

Scheme 3 Plausible mechanism for heterogeneous Cu(I)-catalyzed halodeboronation.

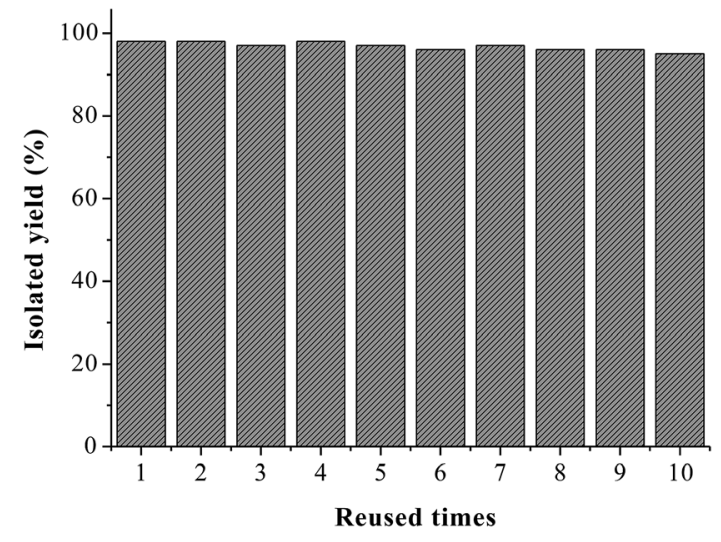

Fig. 1 Recycle of the MCM-41-L-proline-CuCl catalyst.

be $0.83 \mathrm{mmol} \mathrm{g}^{-1}$ after ten consecutive runs, only $1.2 \%$ of copper had been lost from the MCM-41 support. The excellent stability and reusability of the catalyst should be attributed to the chelating action of bidentate L-proline ligand on copper and the mesoporous structure of the MCM-41 support. The result is important from industrial and environmental points of view. The excellent catalytic activity and reusability of the MCM-41-Lproline-CuCl complex make it a highly attractive heterogeneous copper catalyst for the parallel solution phase synthesis of diverse libraries of compounds.

\section{Conclusions}

In conclusion, we have developed the first heterogeneous copper(I)-catalyzed aryl chlorodeboronation reaction by using an $\mathrm{L}^{-}$ proline-functionalized MCM-41-immobilized CuCl complex as catalyst. The present method has some attractive advantages 
such as mild conditions, broad substrate scope, high functional group tolerance, and excellent yields. In addition, this protocol is particularly useful for the conversion of electron-deficient arylboronic acids to aryl chlorides, a transformation that is inefficient in the absence of copper catalysis. More importantly, this heterogeneous copper catalyst can be easily prepared from commercially readily available and inexpensive reagents, and recycled for at least ten times without significant loss of activity, thus making this procedure economically and environmentally more acceptable.

\section{Experimental}

All chemicals were reagent grade and used as purchased. MeCN was dried and distilled before use. The products were purified by flash chromatography on silica gel. A mixture of light petroleum ether $\left(30-60^{\circ} \mathrm{C}\right)$ and ethyl acetate was generally used as eluent. All products were characterized by comparison of their spectra and physical data with authentic samples. ${ }^{1} \mathrm{H}$ NMR spectra were recorded on a Bruker Avance $400(400 \mathrm{MHz})$ spectrometer with TMS as an internal standard in $\mathrm{CDCl}_{3}$ as solvent. ${ }^{13} \mathrm{C}$ NMR spectra were recorded on a Bruker Avance 400 $(100 \mathrm{MHz})$ spectrometer in $\mathrm{CDCl}_{3}$ as solvent. Melting points are uncorrected. Microanalyses were measured by using a Yanaco MT-3 CHN microelemental analyzer. Copper content was determined with inductively coupled plasma atom emission Atomscan16 (ICP-AES, TJA Corporation). The L-prolinefunctionalized MCM-41 (MCM-41-L-proline) was prepared according to our previous procedure. ${ }^{22}$

\section{Preparation of MCM-41-L-proline-CuCl}

In a small Schlenk tube, $1.10 \mathrm{~g}$ of MCM-41-L-proline was mixed with $0.10 \mathrm{~g}(1.0 \mathrm{mmol})$ of $\mathrm{CuCl}$ in $10 \mathrm{~mL}$ of dry acetone. The mixture was stirred at room temperature for $12 \mathrm{~h}$ under an argon atmosphere. The solid product was filtered by suction, washed with acetone and dried at $60^{\circ} \mathrm{C} / 26.7 \mathrm{~Pa}$ under $\mathrm{Ar}$ for $5 \mathrm{~h}$ to give $1.11 \mathrm{~g}$ of a light blue powder copper complex (MCM-41-Lproline-CuCl $[\mathbf{A}])$. The copper content was found to be $0.84 \mathrm{mmol} \mathrm{g}^{-1}$. The MCM-41-L-proline-CuBr [B], MCM-41-Lproline-CuI [C], and MCM-41-L-proline- $\mathrm{CuCl}_{2}$ [D] were also prepared according to a similar procedure from MCM-41-Lproline $(1.10 \mathrm{~g})$ and corresponding copper salts $(1.0 \mathrm{mmol})$, the copper contents were determined to be $0.82 \mathrm{mmol} \mathrm{g}^{-1}$, $0.79 \mathrm{mmol} \mathrm{g}^{-1}$ and $0.80 \mathrm{mmol} \mathrm{g}^{-1}$, respectively.

\section{General procedure for heterogeneous copper-catalyzed chlorodeboronation}

To a solution of arylboronic acid $(0.5 \mathrm{mmol})$ in acetonitrile $(2$ $\mathrm{mL}$ ) were added MCM-41-L-proline-CuCl $[\mathbf{A}](60 \mathrm{mg}, 0.05 \mathrm{mmol})$ and NCS $(0.5 \mathrm{mmol})$. The reaction mixture was stirred at $80{ }^{\circ} \mathrm{C}$ for 12-24 h. After being cooled to room temperature, the mixture was diluted with EtOAc $(15 \mathrm{~mL})$ and filtered. The MCM41-L-proline-CuCl catalyst was washed with acetone $(3 \times 5 \mathrm{~mL})$ and $\mathrm{MeOH}(2 \times 5 \mathrm{~mL})$, and reused in the next run. The organic layer was washed with $1 \mathrm{~N} \mathrm{HCl}, 1 \mathrm{~N} \mathrm{NaOH}$, and brine and dried over $\mathrm{MgSO}_{4}$. After removal of the solvent under reduced pressure, the residue was purified by flash column chromatography on silica gel to provide the desired aryl chloride 2 . Aryl bromides 3a-3i were prepared according to a similar procedure.

\section{Acknowledgements}

Financial supports from the National Natural Science Foundation of China (No. 21462021) and Scientific Research Fund of Education Department of Jiangxi Province (KJLD13022) and Key Laboratory of Functional Small Organic Molecule, Ministry of Education (No. KLFS-KF-201409) are gratefully acknowledged.

\section{References}

1 (a) D. L. Boger, Med. Res. Rev., 2001, 21, 356; (b) B. M. Duggar, Ann. N. Y. Acad. Sci., 2011, 1241, 163; (c) M. H. Ronnest, M. S. Raab, S. Anderhub, S. Boesen, A. Kramer, T. O. Larsen and M. H. Clausen, J. Med. Chem., 2012, 55, 652; (d) M. J. Quinn and D. J. Fitzgerald, Circulation, 1999, 100, 1667; (e) A. Deleon, N. C. Patel and M. L. Crismon, Clin. Ther., 2004, 26, 649; (f) P. I. Hair, P. L. McCormack and M. P. Curran, Drugs, 2008, 68, 1415; $(g)$ G. W. Gribble, Acc. Chem. Res., 1998, 31, 141; (h) G. W. Gribble, Chem. Soc. Rev., 1999, 28, 335.

2 (a) T. Ikawa, T. E. Barder, M. R. Biscoe and S. L. Buchwald, J. Am. Chem. Soc., 2007, 129, 13001; (b) G. C. Fu, Acc. Chem. Res., 2008, 41, 1555; (c) Q. Shen, T. Ogata and J. F. Hartwig, J. Am. Chem. Soc., 2008, 130, 6586; (d) B. P. Fors, D. A. Watson, M. R. Biscoe and S. L. Buchwald, J. Am. Chem. Soc., 2008, 130, 13552; (e) G. A. Molander and D. L. Sandrock, J. Am. Chem. Soc., 2008, 130, 15792; (f) G. D. Vo and J. F. Hartwig, J. Am. Chem. Soc., 2009, 131, 11049.

3 T. Sandmeyer, Chem. Ber., 1884, 1633.

4 R. Taylor, Electrophilic Aromatic Substitution, Wiley, New York, 1990.

5 (a) X. Sun, G. Shan, Y. Sun and Y. Rao, Angew. Chem., Int. Ed., 2013, 52, 4440; (b) X. Shen, A. M. Hyde and S. L. Buchwald, J. Am. Chem. Soc., 2010, 132, 14076.

6 M. Wang, Y. Zhang, T. Wang, C. Wang, D. Xue and J. Xiao, Org. Lett., 2016, 18, 1976.

7 S. M. Maddox, C. J. Nalbandian, D. E. Smith and J. L. Gustafson, Org. Lett., 2015, 17, 1042.

8 (a) H. C. Brown, C. Subrahmanyam, T. Hamaoka, N. Ravindran, D. H. Bowman, S. Misumi, M. K. Unni, V. Somayaji and N. G. Bhat, J. Org. Chem., 1989, 54, 6068; (b) H. C. Brown, T. Hamaoka, N. Ravindran, C. Subrahmanyam, V. Somayaji and N. G. Bhat, J. Org. Chem., 1989, 54, 6075; (c) H. C. Brown, R. C. Larock, S. K. Gupta, S. Rajagopalan and N. G. Bhat, J. Org. Chem., 1989, 54, 6079; (d) D. A. Willis, M. B. McGinnis, G. W. Kabalka and R. M. Pagni, J. Organomet. Chem., 1995, 487, 35; (e) N. A. Petasis and I. A. Zavialov, Tetrahedron Lett., 1996, 37, 567; (f) A. P. Lightfoot, S. J. R. Twiddle and A. Whiting, Tetrahedron Lett., 2004, 45, 8557; $(g)$ A. S. K. Hashmi, T. D. Ramamurthi and F. Rominger, J. Organomet. Chem., 2009, 694, 592; (h) I. A. I. Mkhalid, 
J. H. Barnard, T. B. Marder, J. M. Murphy and J. F. Hartwig, Chem. Rev., 2010, 110, 890.

9 (a) G. W. Kabalka, E. E. Gooch and K. A. R. Sastry, J. Nucl. Med., 1981, 22, 908; (b) G. W. Kabalka, K. A. R. Sastry and P. G. Pagni, J. Radioanal. Chem., 1982, 74, 315; (c) C. Thiebes, G. K. Surya Prakash, N. A. Petasis and G. A. Olah, Synlett, 1998, 141; (d) G. W. Kabalka, M. R. Akula and J. Zhang, Nucl. Med. Biol., 2002, 29, 841; (e) G. W. Kabalka and A. R. Mereddy, Tetrahedron Lett., 2004, 45, 343; (f) R. H. Szumigala, P. N. Devine, D. R. Gauthier and R. P. Volante, J. Org. Chem., 2004, 69, 566; (g) G. W. Kabalka and A. R. Mereddy, Organometallics, 2004, 23, 4519; (h) A. S. L. Thompson, G. W. Kabalka, M. R. Akula and J. W. Huffman, Synthesis, 2005, 547; (i) M.-L. Yao, M. S. Reddy, L. Yong, I. Walfish, D. W. Blevins and G. W. Kabalka, Org. Lett., 2010, 12, 700.

10 (a) J. M. Clough, L. J. Diorazio and D. A. Widdowson, Synlett, 1990, 761; (b) L. J. Diorazio, D. A. Widdowson and J. M. Clough, Tetrahedron, 1992, 48, 8073; (c) T. Furuya and T. Ritter, J. Am. Chem. Soc., 2008, 130, 10060; (d) T. Furuya, H. M. Kaiser and T. Ritter, Angew. Chem., Int. Ed., 2008, 47, 5993; (e) T. Furuya and T. Ritter, Org. Lett., 2009, 11, 2860; $(f)$ C. Cazorla, E. Metay, B. Andrioletti and M. Lemaire, Tetrahedron Lett., 2009, 50, 3936.

11 J. C. Murphy, X. Liao and J. F. Hartwig, J. Am. Chem. Soc., 2007, 129, 15434.

12 H. Wu and J. Hynes Jr, Org. Lett., 2010, 12, 1192.

13 G. A. Molander and L. N. Cavalcanti, J. Org. Chem., 2011, 76, 7195.

14 (a) Y. Iwasawa, Tailored Metal Catalysis, Reidel D. Publishing Company, Dordrecht, Holland, 1986; (b) S. Benyahya, F. Monnier, M. Taillefer, M. Wong Chi Man, C. Bied and F. Ouazzani, Adv. Synth. Catal., 2008, 350, 2205; (c) S. Benyahya, F. Monnier, M. Wong Chi Man, C. Bied, F. Ouazzani and M. Taillefer, Green Chem., 2009, 11, 1121.

15 (a) C. T. Kresge, M. E. Leonowicz, W. J. Roth, J. C. Vartuli and J. S. Beck, Nature, 1992, 359, 710; (b) A. Taguchi and
F. Schuth, Microporous Mesoporous Mater., 2005, 77, 1; (c) R. M. Martin-Aranda and J. Cejka, Top. Catal., 2010, 53, 141; (d) A. Corma, Top. Catal., 1997, 4, 249.

16 J. S. Beck, J. C. Vartuli, W. J. Roth, M. E. Leonowicz, C. T. Kresge, K. D. Schmitt, C. T.-W. Chu, D. H. Olson, E. W. Sheppard, S. B. McCullen, J. B. Higgins and J. L. Schlenker, J. Am. Chem. Soc., 1992, 114, 10834.

17 (a) P. C. Mehnert, D. W. Weaver and J. Y. Ying, J. Am. Chem. Soc., 1998, 120, 12289; (b) K. Mukhopadhyay, B. R. Sarkar and R. V. Chaudhari, J. Am. Chem. Soc., 2002, 124, 9692; (c) J. Y. Ying, C. P. Mehnert and M. S. Wong, Angew. Chem., Int. Ed., 1999, 38, 56; (d) M. Cai, G. Zheng and G. Ding, Green Chem., 2009, 11, 1687; (e) M. Cai, J. Peng, W. Hao and G. Ding, Green Chem., 2011, 13, 190; (f) W. Hao, H. Liu, L. Yin and M. Cai, J. Org. Chem., 2016, 81, 4244.

18 (a) S.-G. Shyu, S.-W. Cheng and D.-L. Tzou, Chem. Commun., 1999, 2337; (b) Y. Yang and R. M. Rioux, Chem. Commun., 2011, 47, 6557.

19 (a) C. D. Nunes, A. A. Valente, M. Pillinger, A. C. Fernandes, C. C. Romao, J. Rocha and I. S. Goncalves, J. Mater. Chem., 2002, 12, 1735; (b) M. Jia, A. Seifert and W. R. Thiel, Chem. Mater., 2003, 15, 2174.

20 (a) A. Corma, E. Gutierrez-Puebla, M. Iglesias, A. Monge, S. Perez-Ferreras and F. Sanchez, Adv. Synth. Catal., 2006, 348, 1899; (b) A. Corma, C. Gonzalez-Arellano, M. Iglesias and F. Sanchez, Angew. Chem., Int. Ed., 2007, 46, 7820; (c) G. Villaverde, A. Corma, M. Iglesias and F. Sanchez, ACS Catal., 2012, 2, 399.

21 (a) R. Xiao, H. Zhao and M. Cai, Tetrahedron, 2013, 69, 5444; (b) H. Zhao, W. He, R. Yao and M. Cai, Adv. Synth. Catal., 2014, 356, 3092; (c) M. Cai, R. Yao, L. Chen and H. Zhao, J. Mol. Catal. A: Chem., 2014, 395, 349; (d) H. Zhao, Y. Jiang, Q. Chen and M. Cai, New J. Chem., 2015, 39, 2106; (e) H. Zhao, W. He, L. Wei and M. Cai, Catal. Sci. Technol., 2016, 6, 1488.

22 C. You, F. Yao, T. Yan and M. Cai, RSC Adv., 2016, 6, 43605. 23 H. E. B. Lempers and R. A. Sheldon, J. Catal., 1998, 175, 62. 